\title{
Autotraducirse en Galicia: ¿bilingüismo o diglosia?
}

\author{
Xosé Manuel Dasilva \\ Universidade de Vigo \\ Departamento de Filoloxía e Traducción \\ Campus Universitario Lagoas-Marcosende \\ 36200 Vigo \\ jdasilva@uvigo.es
}

\section{Resumen}

Este trabajo constituye una aproximación a la realidad del fenómeno de la autotraducción en el espacio gallego. En primer término, se lleva a cabo un breve recorrido a través de la presencia de la autotraducción en la literatura gallega durante del período contemporáneo, desde el siglo XIX hasta el momento actual. A continuación, se pone de relieve la dimensión sociolingüística de la autotraducción cuando se desarrolla entre dos lenguas que mantienen entre sí una relación de desequilibrio. Efectivamente, a través del análisis de las razones expuestas por los autores para sustentar la decisión de autotraducirse y de las características de sus versiones se somete a debate la posibilidad de que nos encontremos ante una actividad de signo diglósico.

Palabras clave: autotraducción, bilingüismo, diglosia, retraducción, historia de la traducción en Galicia.

\begin{abstract}
This work approaches the phenomenon of self-translation within the Galician literary community. Herewith we present a brief review of the occurrence of self-translation in Galician literature from the $19^{\text {th }}$ century to the present day; in addition the work uncovers the sociolinguistic dimension that pertains to translation when practised between two languages of disparaging status. In fact, the possible diglossic nature of self-translation is hereby discussed taking into account the reasons put forward by authors to justify their decision to translate themselves.
\end{abstract}

Key words: self-translation, bilingualism, diglossia, backtranslation, history of translation in Galicia.

La autotraducción es un fenómeno que se encuentra presente de forma más que tangencial en las letras gallegas a lo largo del período contemporáneo. Ya a finales del siglo XIX, en pleno Rexurdimento, cuando el cultivo literario de la lengua propia se reanudaba tras más de cuatrocientos años de silenciamiento, no es difícil encontrar muestras entre los autores más renombrados (Santoyo, 2002: 31, 2005: 865). Se debe tener en cuenta que el primer escritor monolingüe importante de la literatura gallega moderna fue todavía Ramón Cabanillas, cuyas obras comenzaron a aparecer en el primer tercio del siglo XX. 
Efectivamente, Rosalía de Castro tradujo al castellano varios de sus poemas, como «A ventura é traidora» («Tiembla que una inmensa dicha»), «A xusticia pola man» («La justicia por la mano») y « ¡Nin as escuras...!» («Ni a oscuras»), todos ellos del libro Follas novas (Rosa, 1958; López \& Pociña, 1999). Tal labor la llevó a cabo con bastante libertad, cambiando términos y frases, añadiendo elementos textuales o, por el contrario, realizando distintas supresiones que repercuten en el sentido global del poema. A propósito de estas versiones rosalianas, en otro lugar ya planteamos el dilema de si es aconsejable, cuando no legítimo, retraducir aquellos textos que con plena autoridad un autor previamente tradujo a la misma lengua en tanto que propietario intelectual de su obra (Dasilva, 2003c).

Si proseguimos nuestro recorrido, debemos señalar que Curros Enríquez, otro de los escritores gallegos del siglo XIX, también hizo versiones en castellano, entre otros, de los poemas «Tempro deserto» («El templo desierto»), «Sola» («iSola!»), «Ai!» («iAy!») y «Cántiga» («Cántiga»). Es bastante singular, a su vez, el caso de Eduardo Pondal, el tercero de los grandes poetas gallegos del Rexurdimento, puesto que la direccionalidad de sus autotraducciones difirió de lo más común entonces y también más tarde, al trasladar del castellano al gallego, y no al revés, numerosas piezas de Rumores de los pinos, después publicadas bajo el título Queixumes dos pinos.

Con posterioridad, las traducciones de autor volvieron a ser abundantes en la narrativa gallega de posguerra. Álvaro Cunqueiro se autotradujo, por ejemplo, en Merlín e familia (Merlín y familia, 1957), Cando o vello Simbad volva ás illas (Cuando el viejo Simbad vuelva a las islas, 1962) y Xente de aquí e acolá (La otra gente, 1975). Especialmente curioso es lo ocurrido con esta última obra, ya que después de haber sido transferida al castellano por Cunqueiro fue objeto de una retraducción, cuando el escritor ya había fallecido, con el título Gente de aquí y de más allá (1990). En este caso la explicación hay que buscarla en la propiedad de los derechos relativos a la autotradución de Cunqueiro, pertenecientes a la editorial Destino. El interés en publicar la obra por parte de una empresa diferente dio lugar a que fuese necesario hacer una nueva versión a partir del original gallego, una vez comprados los derechos en esta lengua a la editorial Galaxia.

Eduardo Blanco-Amor, otro narrador gallego de posguerra, también se tradujo al castellano, entre otras obras, en A esmorga (La parranda, 1960, 1973), Os biosbardos (Las musarañas, 1975) y Xente ao lonxe (Aquella gente, 1976). Es conveniente destacar, por otra parte, que Blanco-Amor reflexionó en no pocas ocasiones en torno a las versiones de autor, a las que él calificaba con sutil ingenio como «traducciones en carne propia» (Dasilva, 2003a).

Durante la misma época franquista, en el género poético tampoco resulta arduo hallar a diversos autores que se autotradujeron, como Celso Emilio Ferreiro, que trasplantó al castellano varios libros suyos. Cabe citar las versiones de $O$ soño sulagado (El sueño sumergido, 1975), Terra de ningures (Tierra de nadie, 1975), Cemiterio privado (Cementerio privado, 1974) y Onde o mundo se chama Celanova (Donde el mundo se llama Celanova, 1975), aparte de una amplia Antología (1977) de sus versos y de la colección de relatos A fronteira infinda (El alcalde y otros cuentos, 1981), ésta masacrada por la censura cuando salió a la luz en gallego. 
En la obra de Celso Emilio Ferreiro también se produjo la llamativa circunstancia, antes aludida con respecto a Rosalía y Cunqueiro, de que poemas suyos autotraducidos fuesen después vertidos al castellano por un tercero, aunque en este caso contando con la autorización expresa del escritor. Es lo que sucedió con algunas composiciones de Longa noite de pedra (Larga noche de piedra, 1967), como «Cantiga de amigo para Xoán Miró», «O corazón ao vento» y «Formentor», traducidas por Celso Emilio Ferreiro a finales de los años 50 en la revista Papeles de Son Armadans y más tarde trasladadas por varios traductores. Con respecto a estas retraducciones, ni qué decir tiene que resulta un ejercicio altamente sugestivo comparar a tres bandas los originales, las traducciones autoriales y las traducciones alógrafas, a fin de adentrarse en el estudio de la traducción a través de una vía poco habitual.

En este breve repaso acerca de la autotraducción en la historia literaria gallega, ya en el período actual es forzoso dejar constancia principalmente de Manuel Rivas y Suso de Toro. Traducidos ambos algunas veces por manos ajenas, en otras oportunidades decidieron trasladar sus libros en persona. De Manuel Rivas (Dasilva, 2005; Luis Gamallo, 2006) hay que recordar En salvaxe compañia (En salvaje compañía, 1994), Bala perdida (Bala perdida, 1996), A man dos paíños (La mano del emigrante, 2001), As chamadas perdidas (Las llamadas perdidas, 2003), Muller no baño (Mujer en el baño, 2003) y Contos de Nadal (Cuentos de un invierno, 2005). De Suso de Toro mencionemos A sombra cazadora (La sombra cazadora, 1995), Conta saldada (Cuenta saldada, 1997), Calzados Lola (Calzados Lola, 1998), Non volvas (No vuelvas, 2000), Ambulancia (Ambulancia, 2002), Españois todos (Españoles todos, 2004) y Outra idea de España (Otra idea de España, 2005). Ya nos hicimos eco en otro trabajo de la despreocupada osadía de Suso de Toro cuando se traduce, puesto que llegó a resucitar en la versión autotraducida de la novela Ambulancia a un personaje que en el original gallego había muerto (Dasilva, 2002).

Por lo demás, la autotraducción continúa siendo hoy en día una fórmula incesante, para bien o para mal, en la literatura gallega. Baste decir que en los dos últimos años la mayoría de los libros con cierto éxito en el mercado editorial gallego han aparecido en castellano al poco tiempo gracias a versiones autoriales. Como prueba ilustrativa, refiramos los casos de Ollos de auga, de Domingo Villar (Ojos de agua), Ser ou non, de Xurxo Borrazás (La aldea muerta), Herba moura, de Teresa Moure (Hierba mora), As galeras de Normandía, de Ramón Loureiro (Las galeras de Normandía), O señor Lugrís e a negra sombra, de Luís Rei Núñez (El señor Lugrís y la negra sombra), As rulas de Bakunin, de Antón Riveiro Coello (Los hijos de Bakunin) y Fin de século en Palestina, de MiguelAnxo Murado (Fin de siglo en Palestina).

El narrador Carlos Casares tenía ya plena conciencia, hace algunos años, de que la autotraducción es un hábito cada vez más común entre los escritores gallegos. En el año 2000, en una entrevista publicada con el título «Galiza, com todas as letras» en el diario cultural portugués Jornal de Letras, Artes e Ideias, Casares enfatizaba así el cultivo de la autotraducción en la literatura gallega: 
A maioria [de los autores gallegos] escreve em galego, só que muitos escrevem também uma versão em castelhano para que possa ser logo publicada no resto da Espanha.

Hace casi una década, por nuestra parte llamábamos la atención sobre algunas connotaciones de índole sociolingüística que la autotraducción encierra al menos en lo que se refiere al espacio gallego (Dasilva, 1999). No pensamos, sin embargo, que nos equivoquemos mucho si nos atrevemos a aventurar que tales connotaciones afectan de manera similar, con los necesarios ajustes, a las literaturas vasca y catalana. Y es que no es la misma cosa, desde luego, autotraducirse del gallego al castellano y autotraducirse, por ejemplo, del inglés al francés, puesto que un aspecto esencial de la traducción autorial viene dado, a nuestro juicio, por las relaciones de tipo social que se hace necesario discernir en la pareja de lenguas implicadas en dicha operación.

Como punto de partida, argumentábamos en el citado estudio que el Estado español constituye un escenario donde existe una fuerte corriente centrípeta que privilegia como lengua literaria el uso del castellano. En este escenario resulta factible, de tal forma, percibir dos actitudes que no son de ningún modo recíprocas. Por un lado, se observa que desde el centro del Estado no se suele ver con buenos ojos que los textos escritos en castellano se traduzcan a las lenguas periféricas, con excepción tal vez de la literatura infantil y juvenil, donde se descubre un grado superior de tolerancia. Por otro lado, es notorio que la voracidad endocéntrica del Estado reclama que los textos escritos en las lenguas periféricas no solo sean traducidos al castellano, sino que se presenten como verdaderos originales por medio de autotraducciones.

En relación con estas actitudes netamente opuestas, en aquella ocasión alertábamos sobre la existencia de dos amenazas reales en la práctica de la autotraducción dentro del Estado español. En primer lugar, la literatura española tiende a adueñarse de las obras de las literaturas periféricas que aparecen autotraducidas al castellano, propiciando que la identidad lingüística de muchos escritores acabe desvaneciéndose. En segundo lugar, el castellano acostumbra a erigirse en lengua puente en la traducción a otros idiomas de estas obras, contribuyendo a transmitir al público extranjero la idea de que está recibiendo un texto escrito genuinamente en tal lengua.

Conforme un crítico literario gallego apuntaba no sin retranca, en el plano de la literatura no existe, ciertamente, el más mínimo riesgo en la actualidad de que el Estado se pueda desarticular (Ponte Far, 2006). El castellano se impone hegemónicamente como lengua franca para la comunicación entre las literaturas periféricas, y en ese sentido la autotraducción se concibe como el mejor instrumento para que una obra gallega, vasca o catalana sea difundida más allá de sus fronteras lingüísticas. Por mencionar un par de ejemplos, en la versión gallega de la novela Vredaman, del escritor vasco Unai Elorriaga, aparecen como traductores Xesús Carballo Soliño y el propio escritor. Y en la traducción Un tranvía cara a SP, del mismo autor, realizada por Ramón Loureiro, figuran como originales tanto el título en vasco SPrako tranbia como el título en castellano Un tranvía en SP. Ambas 
circunstancias prueban a las claras que las versiones de estas dos novelas se hicieron a partir de las respectivas autotraduciones y no desde el euskera.

Veinticinco años atrás, Gonzalo Torrente Ballester se quejaba del lamentable desconocimiento que se tenía entonces de las literaturas periféricas a la hora de presentar concretamente la versión en castellano de una novela gallega de Carlos Casares:

La publicación en castellano de Ilustrísima, novela de Carlos Casares que vio la luz en lengua gallega, me ofrece la ocasión, que aprovecho del mejor grado, para presentar a los lectores españoles a un escritor parcialmente desconocido. Pero, desconocido, ¿por qué? Aunque suponga una prematura desviación momentánea de mi propósito, quiero coger esta mosca por el rabo y protestar, con toda la vehemencia de que son capaces mis palabras, contra ese ghetto de ignorancia en que el español medio y muy buena parte de los que habitualmente leen, tienen y mantienen a los escritores en lenguas vernáculas. El hecho es irritante, y si por una parte parece mayor la distancia que separa a un español no bilingüe del catalán o del gallego que del francés, por otra no es de creer que las cosas vayan a alcanzar un remedio inmediato, y que el único modo viable de conocer a uno de estos escritores sea el de traducirlo al castellano: lo cual no siempre es fácil, sino más bien excepcional, y por esta razón si el lector típico español sigue desconociendo a vascos, catalanes y gallegos, también éstos se ignoran entre sí. (Torrente Ballester, 1981: 9-10)

En los últimos tiempos, este cuadro se ha visto modificado gracias a un mayor número de versiones en castellano, salvando uno de los impedimentos que el mismo Casares indicaba para que una literatura como la gallega no obtuviese más reconocimiento exterior:

Hai varios problemas. Un deles, que a literatura galega fóra de Galicia practicamente se descoñece, e se a coñecen é a través do castelán. O primeiro paso que dar por un escritor galego é saltar do espazo galego ó español. Necesitas un editor, e non un calquera senón un bo, porque se non tampouco che fai caso ninguén. A partir dese momento xa deches un paso importante, pero a moitos cústalles dalo porque as editoriais están moi metidas no mundo do mercado e apostan case sempre unicamente por libros que teñan moita venda. Isto último tampouco é fácil, porque é algo que non depende só da calidade do libro, senón de moitos factores. O que si é certo é que, por primeira vez, na historia da literatura galega hai bastantes autores galegos traducidos, non só ó castelán senón tamén a outras linguas. Isto é unha novidade absoluta, porque da miña xeración para atrás non hai nada, quitando cousas puntuais. E por iso nunca se estivo tan ben coma agora. (Fortes, 2002a: 63)

Ahora bien, un escritor periférico del Estado español para llegar hoy en día más allá no solo debe ser traducido, sino que suele tener que pagar el tributo de la autotraducción, asumiendo de alguna manera la condición subalterna de su lengua original. Hasta tal punto es así que la negativa de un autor a autotraducirse puede considerarse como un gesto de reivindicación de su propia identidad cultural. En lo que respecta particularmente a las letras gallegas, es preciso reconocer que nunca 
como ahora se tradujo tanto al castellano, pero en igual medida tampoco hubo como en la actualidad tantas autotraducciones, paso previo, como antes subrayábamos, para proyectarse a otros países (Dasilva, 2003b). Suso de Toro recordaba con qué insistencia, tras poner en castellano su primer libro, algunos le decían que escribiese directamente en esta lengua, como si ya indirectamente lo hiciese al autotraducirse:

Pero cuando llegué a Madrid con mi primer libro traducido y editado en castellano, hubo quien no pudo reprimir esa incomodidad que embarga a tantos y me lo preguntó. Me preguntó lo que siempre está ahí: «¿Y por qué no escribes directamente en castellano? Serían libros más universales, llegarían a más lectores». (Toro, 1996: 24)

El traductor Miguel Sáenz afirmó que, de inicio, nadie está en mejor condiciones que un autor para traducir una obra suya, siempre que domine, como es natural, tanto la lengua de partida como la lengua de llegada, aunque a continuación no dejaba de matizar que en la práctica no todo es tan simple (Sáenz, 1993: 112). Helena Tanqueiro demostró con tino que un escritor puede conseguir, sobre todo si asume el rol de traductor, un producto autotraducido con las mismas garantías que el de cualquier traductor profesional (Tanqueiro, 1999, 2005). Georges Steiner reveló, a propósito de Beckett, que el bilingüismo de este escritor es tan perfecto que transfiere, en mejores condiciones que otro traductor, sus agudezas verbales sin perder en el camino la más mínima dosis de expresividad (Steiner, 1973, 32). Carlos Casares, a su vez, en la última fase de su carrera literaria llegaba al siguiente convencimiento:

He decidido que de todo lo que escriba haré yo mismo la versión castellana. Creo que la traducción está justificada cuando alguien no conoce el idioma, pero si se conocen los dos, es absurdo buscar un traductor. El mejor traductor es uno mismo. (Riera, 1997: 73)

Desde una perspectiva general, no hay ningún obstáculo para que convengamos que la autotraducción es un acto que presupone por principio a una persona bilingüe que actúa como autor y traductor de su obra, tal y como la siguiente definición recoge:

Self-translation as I understand it means that the author of a literary text completed in one language subsequently reproduces it in a second language. (Whyte, 2002: 64)

Con todo, esta sencilla definición se complica cuando tal persona desarrolla su actividad, más que a nivel individual, en el seno de una comunidad también bilingüe en la que existe una descompensación patente entre las dos lenguas que comparten el mismo espacio geográfico. Por eso esgrimíamos más arriba que es necesario atender de modo especial a la autotraducción que se produce desde una lengua minorizada a una lengua normal, puesto que no constituye un fenómeno 
equiparable al transvase que tiene lugar entre dos idiomas que gozan de análoga consideración social. En aquel caso, lo que en principio sería una actividad bilingüe se convierte muchas veces, aunque se lleve a cabo de forma inocente, en una actividad diglósica.

Fijémonos en los motivos alegados comúnmente por los escritores gallegos para autotraducirse. Algunas veces se han referido a la mayor confianza que les inspiraba una versión realizada por ellos frente al trabajo de otro traductor, a pesar de que al mismo tiempo reconocían que la tarea de traducirse a otra lengua es muy pesada. Véase, por ejemplo, lo que el periodista y novelista Carlos G. Reigosa explicaba:

¿Cal é o problema canso se encarga outra persoa de facer a tradución? Eu só teño una obra traducida ó castelán por outro escritor, que fixo una versión magnífica, pero ó final non puiden resistir a tentación de sentarme con el e reparar liña por liña, porque discrepas. O malo é que ó saber as dúas linguas, máis ou menos ben, non coincides. E advírteslle: «Eu aquí puxen fantástico, no sentido de espléndido, non no sentido de incrible». Ese tipo de cousas son as que levan a que traduzas ti, pese a que o proceso representa unha tortura grande. (Caño, 2007: 219)

Carlos Casares hizo referencia a aquello que le movió por primera vez a traducir personalmente la novela Os mortos daquel verán. Con suma franqueza confesó que le producía, en lo referente al estilo de este libro, una cierta sensación de inseguridad el trabajo de cualquier traductor:

Está escrito en linguaxe administrativa, digamos así, é un funcionario que escribe dun modo moi específico. Receei que un tradutor non cumprise exactamente aquilo que eu pretendía e así fixen eu mesmo a tradución. Foi a única vez que o fixen, efectivamente. (Moutinho, 2004: 125)

Puede aceptarse la naturaleza socialmente neutra de estas causas para que un autor decida verterse a otra lengua. Sin embargo, no se hace costoso distinguir indicios de una forma de pensar diglósica en otros motivos en ocasiones aducidos. Que si la autotraducción, en primer lugar, le permite al escritor periférico alcanzar una mayor difusión para su obra, con la posibilidad de penetrar en el mercado hispanoamericano. Que si la autotraducción, por otra parte, facilita la profesionalización del escritor que trabaja con una lengua minoritaria — por ejemplo, a través del periodismo-, aprovechando que la línea divisoria entre el autor monolingüe que se autotraduce y el autor bilingüe es muy tenue. Obsérvese cómo Suso de Toro se mostraba consciente de este problema a la hora de plantear la elección de un idioma con el objeto de vivir de la actividad intelectual:

Aunque precisamente la batalla que estamos dando los escritores actuales es poder escribir en gallego y no tener que emigrar para vivir de nuestro trabajo. Que las opciones de irse o escoger el idioma sean libres, no impuestas por la necesidad. (Toro, 1998: 62) 
Carlos Casares expuso el compromiso cívico que entraña cultivar una lengua minorizada, pudiendo abrazar otra de más amplios horizontes:

Síntome escritor dunha lingua minorizada e responsábel por iso. Doutra maneira escribiría en castelán. Para min escribir en galego non ten máis que problemas e tería máis posibilidades facéndoo en castelán, tanto no plano da creación literaria como no xornalismo. Podería ir a Madrid e dedicarme á literatura exclusivamente. Para min é clarísimo que pertenzo a unha lingua non normalizada, e esa conciencia é a que me inclina a limitarme e perder oportunidades. (Carballa, 1996: 13)

Esta militancia idiomática contrasta con una cierta propensión hacia la extraterritorialidad lingüística que algunos autores periféricos exhiben a veces:

En relación conmigo hay un tema que sale siempre, el tema de la identidad nacional. Yo sólo digo que soy escritor, ni gallego ni castellano, escritor sin apellido. Ahora bien, soy gallego de nación, por origen y por convicción cívica. El gallego es mi idioma nacional, pero al mismo tiempo el castellano es también un idioma mío, con lo cual podría decir que soy español en sentido amplio [...]. (Vega, 2002: 58)

En fin, otro motivo de carácter diglósico a menudo expuesto es que la autotraducción permite superar la insatisfacción a que puede dar lugar la recepción de la obra original, como sostenía de nuevo Suso de Toro en una entrevista periodística:

Hai un ano e medio publiquei Home sen nome, una novela na que botei o resto, traballei con toda a forza da que fun quen, implicado literaria e humanamente ao máximo: aínda hoxe non sei que significa o libro para iso que chaman sistema literario galego, a literatura galega. Non sei se a miña obra é insignificante ou foi lida con atención, se dura. Polo tanto, como escritor, un sistema literario que non recibe a miña obra, que non sei como nin de que xeito me recibe, para min non existe.

No era la primera vez que Suso de Toro echaba mano de este motivo para autotraducirse, dado que en otra oportunidad ya se había referido a que sus libros tenían mejor acogida en otros lugares:

Seguirei publicando en galego en Galicia. Pero o que non quero é depender do que se diga dos meus libros aquí, dóeme demasiado. Teño experiencias prolongadas, e tamén recentes, moi duras, sobre todo as do ano 2000, en que saquei dous libros: Non volvas e $O$ país das brétemas, que é un cruce de ensaio literario con reivindicación dunha parte da mitoloxía cultural celta, e que contén parte da miña estética. Este libro nin sequera foi reseñado, que eu saiba, en Galicia. E, por outra parte, Non volvas foi unha novela que presentei sen éxito durante dous anos a cinco certames literarios. É moi duro que lle pase isto a unha obra túa que consideras valiosa, faiche pensar que o que escribes non ten ningún mérito. En cambio, fóra de Galicia os meus libros son tratados cun respecto exquisito. (Fortes, 2002b: 61) 
Sin percatarse de que el contexto gallego no disfruta de una situación de normalidad, al igual que lo que ocurre con la lengua, que favorezca el procesamiento de toda la literatura que genera, Suso de Toro perseveraba en el mismo pretexto:

Da miña novela Land Rover, teño unha única crítica editada na prensa galega... Teño recensións en francés, en italiano, en español... Pero é que a prensa galega só comezou a falar aquí dela a partir do momento en que foi traducida e editada en español e apareceu reflectida pola prensa española. É unha experiencia que temos os autores traducidos ó español. (Navaza; Toro, 2001: 69)

Dígase de paso que este motivo fue empleado por el escritor gallego Alfredo Conde para legitimar no ya sus autotraducciones, sino su deserción lingüística cuando se presentó, para sorpresa de todos sus colegas, al premio Nadal con la obra Los otros días, escrita en castellano. Para él, su libro anterior, Música sacra, de modo injusto no había tenido apenas éxito en Galicia, mientras que la correspondiente versión en castellano era recibida en el resto del Estado español con mejor suerte.

Lo cierto es que resulta altamente sorprendente comprobar de qué forma coinciden bastantes de los motivos manejados por parte de algunos autores gallegos - y también, mutatis mutandis, de algunos autores vascos y catalanes- para explicar sus autotraducciones y aquellas disculpas que daban los escritores portugueses cuando, durante los siglos XVI y XVII, se agudizó en territorio luso el uso del castellano como lengua literaria (Vázquez Cuesta, 1988). Repárese en lo que decía Pedro Nunes después de poner en este idioma su Libro de algebra (1567):

E primeiramente a escrevi em nossa língua portuguesa [...], mas depois considerando que o bem quanto mais comum e universal, tanto é mais excelente e porque a língua castelhana é mais comum em toda Espanha que a nossa, por esta causa a quis trasladar em língua castelhana, para nela se haver de imprimir, porque não careça dela aquela nação tanto nossa vizinha, com a qual tanto comunicamos e tanta amizade temos. (Dasilva, 2006: 15)

Pedro Teixeira incluía esta razón en sus Relaciones [...] del origen, descendencia y sucesión de los reyes de Persia y Harmus... (1610):

Primero escribí estas relaciones en mi lengua materna portuguesa, [...] y queriendo imprimir por licencia que ya para ello tenía mudé de parecer, obligado de la instancia y consejo de amigos, y púselo en lengua castellana [...] juzgando que en esta lengua quedaba más comunicable y mi patria antes recibía servicio que ofensa. (Dasilva, 2006: 33)

Atiéndase, por último, a lo que afirmaba António de Sousa Macedo en su obra Flores de España, excelencias de Portugal (1631):

Y perdonad si, dejada la excelente lengua portuguesa, escribo en la castellana, porque como mi intento es pregonaros por el mundo, he usado por más universal ésta y porque también los portugueses saben estas excelencias y así para ellos no es menester escribirlas. (Dasilva, 2006: 41) 
Hay que considerar que el escritor periférico que se autotraduce en el Estado español es bilingüe, pero no exófono. Esta circunstancia tiene su influencia en el hecho de que tal escritor - muchas veces incluso sin que se le pidan cuentas- tienda a justificar sus versiones autoriales con los motivos de carácter diglósico que acabamos de ver. Por otro lado, es preciso resaltar que la propia autotraducción desde una lengua minorizada como el gallego a una lengua completamente normalizada como el castellano también suele presentar en sí algunas características en cierto modo diglósicas.

En primer término, bajo ese ángulo cabe interpretar que se oculte en los títulos de crédito de la autotraducción que lo que el lector tiene en sus manos es una versión realizada desde otra lengua. Esto tiene como efecto inmediato que la nacionalidad literaria del escritor en cuestión se difumine, de tal forma que no es de extrañar que después se acuse al ISBN — sin razón, todo hay que decirlode «distorsionar la imagen del polisistema interliterario en España» (Van Hooft, 2004: 316). Como sin mucho esfuerzo se puede constatar, el propósito de quien hace esto es formar parte al mismo tiempo de dos literaturas. Alfredo Conde, traductor sistemático de sus obras al castellano, representa una muestra elocuente de este tipo de comportamiento. Tanto es así que incluso no parece ni mucho menos casual que los títulos que escoge para sus libros tengan siempre una idéntica forma en gallego y en castellano: Breixo (1981), Memoria de Noa (1984), El Griffón (1987), Música sacra (1990), Siempre me matan (1995), Azul cobalto (2002), Memoria de soldado (2002), Romasanta (2004), Lukumí (2006) y María de las batallas (2008).

En segundo lugar, otro síntoma de diglosia es que salgan al mercado casi a la vez el original y la autotraducción. Grutman estableció una distinción muy pertinente entre las denominadas «simultaneous auto-translations», es decir, las autotraducciones que surgen durante el proceso de escritura, y las «delayed auto-translations», esto es, aquellas que aparecen algún tiempo después de haber sido publicado el original (Grutman, 1998: 19). No es fruto del azar que muchas autotraducciones del gallego al castellano pertenezcan al primer tipo. El escritor Xosé Miranda indicó irónicamente que estas versiones responden a un cierto efecto sopistant, constituyendo un serio peligro para las ediciones originales desde el momento en que se convierten en poderosas competidoras (Miranda, 2007: 23).

En tercer lugar, una característica diglósica más de las autotraducciones entre una lengua minorizada y una lengua normalizada es su direccionalidad. Resulta bastante habitual que se trasladen al castellano las obras escritas originalmente en gallego, como ya hemos advertido, y cada vez más, pero difícilmente se autotraducen a esta lengua las obras en castellano de escritores gallegos. De los autores de fortuna más reciente en el mercado español, como Luisa Castro, Susana Fortes, Marta Rivera de la Cruz o Ramón Pernas, no es posible ofrecer ni tan siquiera una muestra. En este caso existe una clara diferencia entre el gallego y el catalán, que sí dispone de versiones - aunque no autotraducciones, lo que es muy significativode, por ejemplo, Soldados de Salamina (Soldats de Salamina) y La velocidad de la luz (La velocitat de la llun), de Javier Cercas, o de La sombra del viento (L'ombra del vent), de Carlos Ruiz Zafón. 
Podríamos seguir enumerando otras características diglósicas de las autotraducciones gallegas, como por ejemplo que una buena parte de los autores que se traducen a sí mismos nunca hayan tenido el más mínimo contacto con la experiencia de verter a otros escritores. O como la idea de que la lectura de la autotraducción al castellano sea la prueba de fuego para comprobar la calidad de una obra, algo que por muy impensable que parezca ha defendido con total desfachatez Alfredo Conde, quien por cierto recibió el Premio Nacional de Literatura por una obra no escrita originalmente en castellano (El Griffón, 1986), aunque sí autotraducida, un detalle que también es muy expresivo:

Llegado aquí es cuando ya puedo confesar que empecé traduciéndome para hacerme valer como escritor, para poder reconocerme como tal, sabedor que era ya entonces de dos verdades, a saber: que no somos lo que somos, sino lo que nos reconocen que somos, la primera; y, la segunda, que una novela que no funciona en otro idioma distinto de aquel en el que fue escrita es porque tampoco lo hace en el original [...]. A mí las mías no me parecían malas, como ya dije antes, y necesitaba constatarlo, sometiéndolas al banco de pruebas de la traducción y de la crítica. Fue así de simple. (Conde, 2002: 25)

Tan solo queremos dedicar un último comentario a aquello que acaso sea una de las señales más evidentes de diglosia en bastantes de las autotraducciones desde una lengua minorizada. Se trata de una característica — al igual que otras descritas antes- que no es privativa de dichas versiones, pero que de forma más acusada se da en ellas. Nos referimos al hecho de que sea frecuente en tales autotraducciones una nítida desproporción entre las dos facetas del autotraductor como autor y como traductor en favor de la primera de éstas.

Efectivamente, nos encontramos en muchas ocasiones ante auténticas refundiciones, hasta el punto de que, como sugería Oustinoff, aquí «les oppositions traditionnelles entre original et traduction et entre auteur et traducteur n'ont plus lieu d'être» (Oustinoff, 2003: 85). De acuerdo con la tipología esbozada por el mismo Oustinoff, se verifica que las versiones autoriales realizadas desde un idioma subordinado aspiran a ser primordialmente auto-traductions (re)créatrices, esto es, productos en los que sobresale una actuación omnímoda del autor al trasladar su texto a otra lengua (Oustinoff, 2001: 33-34).

Según la formulación de Fitch, el resultado en este último caso es un texto traducido que, en lugar de suponer un reflejo del texto de partida, se transmuta más bien en una creación artística autónoma (1985, 1988: 124-140). Citemos un ejemplo gallego reciente: la versión autotraducida al castellano de la novela Ser ou non, de Xurxo Borrazás, no sólo tiene un título distinto (La aldea muerta), sino que incluso se puede decir que se trata de una ficción en líneas generales independiente, tal es la cantidad de modificaciones de todo tipo que incorpora.

Paradójicamente, antes ocurría que se declaraba abiertamente esta estrategia autotraductora en algún sitio de la versión para que el lector no se llamase a engaño, mientras que ahora muchas veces predomina, como ya hemos visto, la ocultación de cualquier dato que impida presentar como original lo que realmente es una 
traducción. Con respecto al pasado, véase lo que decía con honestidad Eduardo Blanco-Amor al comienzo de Las musarañas, versión autotraducida del libro Os biosbardos, en un prólogo precisamente titulado «Justificación»:

No tengo lugar para más. Pienso, incluso, que pudo resumirse en la aclaración de que estas traducciones son versiones, que por pertenecer a un mismo autor, pues, gozan de cierta franquicia para modificar, claro que sin llegar al abusivo gato por liebre. Quedan, pues, avisados los lectores bilingües. No hubo dolo ni malicia, sino procedimiento técnico, para decirlo con una palabra precautoria, que espero no empeore, aún más, estos apacibles relatos, pensados, y, lo que es más comprometedor, sentidos en otra lengua. (Dasilva, 2003a: 298)

Celso Emilio Ferreiro hacía lo propio en una nota que encabeza El alcalde y otros cuentos, traducción autorial de A frontera infinda:

Los cuentos incluidos en este libro — salvo «El alcalde» $\mathrm{y}$ «El tímido»—- fueron escritos en lengua gallega y publicados con el título de A fronteira infinda (La frontera infinita) por Ediciones Castrelos de Vigo, en 1972. Su traducción, que ahora ofrecemos en El alcalde y otros cuentos, ha sido realizada por el propio autor con un designio exclusivamente literario, es decir, siguiendo el hilo argumental primitivo, pero en muchos casos sin someterse necesariamente a un criterio de literalidad léxica.

Damos aquí fin a nuestro análisis. Solamente queremos poner de manifiesto, antes de terminar, que en las páginas anteriores hemos pretendido dar cuenta de una perspectiva que es imprescindible en el estudio de la autotraducción cuando ésta tiene lugar entre dos idiomas de jerarquía desigual. Nuestra atención se ha fijado sobre todo en el panorama gallego, pero volvemos a insistir en que no resultaría un despropósito extender algunas conclusiones a otros ámbitos en los que se aprecia una situación semejante.

\section{Bibliografía}

CAÑo, Xosé Manuel del (2007). O misterio de Carlos G. Reigosa. Conversas. Vigo: Edicións Xerais de Galicia.

Carballa, Xan (1996). «Carlos Casares». A Nosa Terra, 720: 12-13.

CondE, Alfredo (2002). «La autotraducción como creación». Quimera, 210: 20-26.

Dasilva, Xosé Manuel (1999). «Cinco lustros de traducción literaria en Galicia». Ínsula, 629: 9-11.

- (2002). «Competencia bilingüe e autotradución en Galicia —algúns apuntamentos». En: VIII Conferencia Internacional de linguas minoritarias / VIII Internacional conference on minority languages. Santiago de Compostela: Xunta de Galicia, 441-452.

- (2003a). Babel entre nós. Escolma de textos sobre a tradución en Galicia. Vigo: Universidade de Vigo.

- (2003b). «Michaël Oustinoff, Bilinguisme d'écriture et auto-traduction (Julien Green, Samuel Beckett, Vladimir Nabokov)». Boletín Galego de Literatura, 29: 230-235.

- (2003c). «Rosalía traducida para hispanófonos». Grial, 160: 114-116. 
- (2005). «As chamadas perdidas de Manuel Rivas vertidas en lingua portuguesa». En: Dasilva, Xosé Manuel (ed.), Perfiles de la traducción hispano-portuguesa I. Vigo: Universidade de Vigo, 131-139.

- (2006). Babel ibérico. Antología de textos críticos sobre la literatura portuguesa traducida en España. Vigo: Universidade de Vigo.

FITCH, Brian T. (1985). «The Status of Self-Translation». Revue de Critique et de Théorie Littéraire, 4: 111-125.

- (1988). Beckett and Babel: An Investigation into the Status of the Bilingual Work. Toronto: University of Toronto Press.

ForTes, Belén (2002a). «Carlos Casares, palabra de escritor». Tempos, 56: 60-66.

- (2002b). «Suso de Toro. Sonoras desidencias». Tempos, 60: 56-61.

Grutman, Rainier (1998). «Auto-translation». En: BAKER, Mona (ed.), Roudletge Encyclopedia of Translation Studies. Londres \& Nueva York: Roudletge, 17-20.

Hooft Comajuncosas, Andreu van (2004). «¿Un espacio literario intercultural en España? El polisistema interliterario en el Estado español a partir de la traducciones de las obras pertenecientes a los sistema literarios vasco, gallego, catalán y español (1999-2003)». En: Abuín González, Anxo; TARrío Varela, Anxo (eds.), Bases metodolóxicas para unha historia comparada das literaturas na Península Ibérica. Santiago de Compostela: Universidade de Santiago de Compostela, 313-333.

LóPEZ, Aurora; PociÑA, Andrés (1999). «Sobre as traduccións feitas por Rosalía». En: ÁlVAREZ, Rosario; VIlaVedra, Dolores (eds.), Cinguidos por unha arela común. Homenaxe ó profesor Xesús Alonso Montero, vol. 2. Santiago de Compostela: Universidade de Santiago de Compostela, 813-827.

Luis Gamallo, María (2006). «Manuel Rivas: de l'oeuvre autotraduite à la traduction ou l'analyse des enjeux idéologiques voire politiques de la traduction». En: HiBBS, Solange; Martínez, Monique (eds.), Traduction, Adaptation, Réécriture dans le Monde Hispanique Contemporain. Tolosa: Presses Universitaires du Mirail, 61-75.

Miranda, Xosé (2007). «Problemas da literatura galega: editoriais, críticos, libreiros, xornais...». A Nosa Terra, 1253: 23.

Moutinho, José Viale (2004). «A alegría de o escoitar». En: CARballa, Xan; Villalaín, Damián (eds.), Carlos Casares. Os amigos, as imaxes, as palabras. Vigo: Promocións Culturais Galegas, 45-46.

NavaZA, Gonzalo; Toro, Suso de (2001). «A creación literaria como provocación». 48: 66-72.

OustinOFF, Michaël (2001). Bilinguisme d'écriture et auto-traduction (Julien Green, Samuel Beckett, Vladimir Nabokov). París: L'Harmattan.

- (2003). La traduction. París: Presses Universitaires de France.

PonTE FAR, José A. «Articulación literaria», La Voz de Galicia, 22-IV-2006.

RIERA, Miguel (1997). «De lenguas, tradiciones literarias y otros griales. Entrevista a Carlos Casares». Quimera, 158-159: 69-74.

Rosa, Alberto Machado da (1958). «Subsídios para uma edição crítica. Traduções nãocoleccionadas de Rosalía de Castro». En: Homaxe a Ramón Otero Pedrayo. Vigo: Editorial Galaxia, 219-236.

SÁENZ, Miguel (1993). «Autor y traductor». Senez, 9: 103-118.

SANTOYO, Julio-César (2002). «Traducciones de autor: una mirada retrospectiva». Quimera, 210: 27-32.

- (2005). «Autotraducciones: una perspectiva histórica». Meta, L: 858-867.

- (2006). «Traducciones de autor (self-translations): materiales para una bibliografía básica». Interculturalidad y Traducción, 2: 201-236. 
STEINER, George (1973). Extraterritorial (Ensayos sobre literatura y la revolución lingüística). Barcelona: Barral Editores. Título original: Extraterritorial -Papers on literatura \& the language revolution (1971). Trad.: Francisco Rivera.

TANQUEIRO, Helena (1999). «Un traductor privilegiado: el autotraductor». Quaderns. Revista de traducció, 3: 19-27.

- (2005). «A tradução para português de uma obra autotraduzida». En: DAsILVA, Xosé Manuel (ed.), Perfiles de la traducción hispano-portuguesa I. Vigo: Universidade de Vigo, 73-82.

Toro, Suso de (1996). «Mi pregunta mágica: ¿escribir en gallego?». Galicia, 669: 22-25. - (1998). «A ver si ahora...». Ajoblanco, 63: 62-64.

Torrente Ballester, Gonzalo (1981). «Prólogo». En: Casares, Carlos, Ilustrísima. Barcelona: Luis de Caralt Editor, 9-16.

VÁzQuez Cuesta, Pilar (1988). A Língua e a Cultura Portuguesas no Tempo dos Filipes. Mem Martins: Publicações Europa-América.

VEGA, Rexina R. (2002). «La modernidad amordazada de Galicia. Entrevista a Suso de Toro». Quimera, 213: 56-63.

Whyte, Christopher (2002). «Against Self-Translation». Translation Literature, 11: 64-71. 